\title{
Cidade, pedagogia e rap
}

\author{
City, pedagogy and rap
}

Ciudad, pedagogía y rap Paula Guerra - Universidade do Porto - FLUP | Faculdade de Letras, Departamento de Sociologia |
PORTO | Portugal. E-mail: mariadeguerra@gmail.com | (1)

Resumo: O rap é a banda sonora de muitas cidades, especialmente de certas zonas desfavorecidas nas cidades portuguesas. Os jovens usam a música para reverter a sua situação de marginalização, criticar a sociedade que os marginaliza, mas, também, como um veículo de mobilização comunitária. Assim, procuramos analisar as representações sobre a cidade evidenciadas em quatro canções rap portuguesas através das principais temáticas abordadas cruzadas simultaneamente com questões étnicas imanentes ao capital subcultural racializado. Esta análise é crucial para apreendermos a importância das criações artísticas contemporâneas de forma dialógica, como reflexo das complexidades societais e formas de representação e de intervenção sociais. Esta condição é outrossim uma demonstração das virtualidades do rap como instrumento pedagógico.

Palavras-chave: Pedagogia. Rap. Cidade.

Abstract: Rap is the soundtrack of many cities, especially from certain disadvantaged areas in Portuguese cities. Young people use music to reverse their marginalization, to criticize the society that marginalizes them, but also as a vehicle for community mobilization. Thus, we seek to analyze the representations about the city showed in four Portuguese rap songs, through the key themes dealt simultaneously with ethnic issues inherent to the racialized subcultural capital. This analysis is crucial to grasp the importance of contemporary artistic creations in a dialogical way, as a reflection of societal complexities, but also as forms of social representation and intervention. This condition is also a demonstration of the virtualities of rap as a pedagogical instrument.

Keywords: Pedagogy. Rap. City. 
Resumen: El rap es la banda sonora de muchas ciudades, especialmente ciertas áreas desfavorecidas en las ciudades portuguesas. Los jóvenes usan la música para revertir su marginación, criticar a la sociedad que los margina, pero también como un vehículo para la movilización de la comunidad. Por lo tanto, buscamos analizar las representaciones de la ciudad evidenciadas en cuatro canciones de rap portugués a través de los temas principales abordados simultáneamente con cuestiones étnicas inmanentes al capital subcultural racializado. Este análisis es crucial para comprender la importancia de las creaciones artísticas contemporáneas de una manera dialógica, como un reflejo de las complejidades sociales y las formas de representación e intervención social. Esta condición es también una demostración de las virtualidades del rap como instrumento pedagógico.

Palabras clave: Pedagogía. Rap. Ciudad. 


\section{A força da palavra}

Parece um lugar-comum, mas o mundo encontra-se em profunda mudança. Sobretudo porque a vertigem da mudança é cada vez maior. E uma das faces mais visíveis dessa mudança advém do facto de uma crescente parte da população ficar para trás. Pessoas que acabam por se tornar invisíveis e alvo de análises essencializadas. Deixam de deter a sua especificidade individual, deixam de ser pessoas, para apenas serem consideradas como uma massa indiferenciada. E uma massa social desvalorizada. Isso é mais do que conhecido nas cidades da nova marginalidade urbana avançada (WACQUANT, 2014). Com a rutura do contrato social fordista-keynesiano, franjas crescentes de população são colocadas à margem da cidade ocupam a não-cidade (AUGÉ, 2012). Aquelas zonas da cidade escondidas, as suas traseiras. Zonas estigmatizadas que apenas conhecemos pelas notícias sensacionalistas dos média.

É premente romper com estas dinâmicas excludentes. E a melhor forma é através da educação. Mas, e como veremos mais à frente, não todas as formas de educação. Não se pretende uma educação preocupada unicamente em transmitir acriticamente o conhecimento do professor para o aluno através de uma relação não-comunicativa. Em vez disso, procuraremos fazer um apelo a uma pedagogia não formal, que passa, neste caso em concreto, pela apologia do rap, apropriando-nos do seu potencial de denúncia, nomeadamente sobre a crise da habitação, o racismo, a violência policial nos bairros degradados, a falta de futuro dos jovens de minorias étnicas, entre outras temáticas. Não pretendemos utilizar o rap apenas pelo facto de ser uma novidade, ou uma concessão ao facilitismo, mas porque julgamos que se trata de um género com potencial para ser um veículo pedagógico para levar a cabo os preceitos de Freire (2005), ou seja, a formação de (estudantes) cidadãs e cidadãos críticos e participativos, preocupados em mudar a sociedade, em romper com a crescente polarização societal, mais preocupada em criar muros $e$ não pontes.

Neste sentido, para além da componente contestatária, esta nova pedagogia que advogamos pode servir para mitigar o individualismo e a atomização social. Mas mais do que isso: o niilismo que advém da sensação de que todos estes problemas sociais estão para além das nossas capacidades de ação. Uma consequência da lógica política que parece apenas se preocupar com o macro e com números e construções grandiosas. Calvino (2009) transmite, mais literariamente, essa preocupação com a cidade de Ersília. Nesta cidade, os seus habitantes para 
assinalarem as relações pessoais entre eles estendiam fios de várias cores entre as esquinas das casas, como símbolo das intensas relações de sociabilidade. Não se pretende abandonar a cidade, como aconteceu com Ersília, quando os fios se tornaram tantos que se tornou impossível lidar com eles. Pretende-se gizar nas cidades "teias de relações intricadas que procuram uma forma" (CALVINO, 2009, p. 83). Todavia, inquietar-nos com a cidade, ou com a sociedade, não nos deve levar a desviar o olhar dos problemas que afetam os indivíduos. Isto é, a análise dos problemas sociais não nos deve fazer esquecer a complexidade do indivíduo. O que explica a virtualidade do rap: enquanto canção de protesto ancorada numa trajetória individual, num percurso marcado por múltiplas exclusões e desigualdades.

Assim, organizamos a nossa argumentação em quatro momentos essenciais. Num primeiro momento, analisaremos o rap em Portugal, enquanto uma das principais faces do protesto juvenil, especialmente após a crise financeira de 2008; em seguida, examinaremos de forma sucinta o que consideramos por pedagogia rap e as suas virtualidades para responder à crescente marginalidade urbana avançada; num terceiro momento, exibiremos as nossas opções metodológicas e, por fim, dissecaremos criticamente, analisando as visões (e preocupações) sobre a cidade, quatro canções de rap português.

\section{O rap como a face visível do protesto urbano contemporâneo}

O rap estabelece-se no espaço urbano. O seu poder advém da forma como expressa politicamente as tensões existentes no espaço urbano. Na sua génese, o rap surgiu no Bronx, em clara resposta às políticas urbanas falhadas de renovação urbana. E rapidamente se estendeu por todo o globo como uma forma de música de protesto e de resistência. Trata-se de um género musical capaz de estabelecer pontes com as experiências de vida dos mais desfavorecidos e marginalizados. Mas também possui uma forte capacidade de mobilização política. É relevante referir, neste artigo, que o rap ter sido a banda-sonora da revolução egípcia e tunisiana. Nestes dois casos, o rap serviu para moldar subjetivamente o quadro de pensamento das pessoas, através das suas letras críticas perante os regimes e as condições de vida; em seguida, os músicos davam concertos na rua, durante as manifestações, o que servia para levar as multidões para um estado emocional, uma forma de efervescência coletiva (LEVIE, 2015). 
O espaço urbano, para Sánchez García e Feixa Pàmpols (2020), é um território musical, com discursos contraditórios e alvo de lutas. Assim, cada local, seja uma cidade ou bairro degradado, tem a possibilidade de criar narrativas específicas advindas de experiências de vida. Tal pode ser visto no rap português. Aqui, o espaço é também de extraordinária importância (FRADIQUE, 2003). Se nos situarmos na análise das letras das canções, encontramos várias referências ao espaço, nomeadamente ao bairro, à rua e à cidade. Os bairros (desfavorecidos) possuem uma dupla simbologia. Primeiro, são o símbolo da sua exclusão e das suas condições de vida: são o padrão de vida que atiram à face da sociedade que os discrimina. Segundo, e paradoxalmente, são também reconvertidos como espaços agregadores das suas identidades e de um sentimento ontológico de pertença.

Fradique (2003) considera que presenciamos uma reconversão de um não-lugar para um lugar identitário por via das canções de rap. Porém, nem sempre este lugar se constrói positivamente. Como se falou anteriormente, o rap no espaço urbano marca-se por discursos contraditórios. Se por um lado, como veremos nas canções analisadas, alguns procuram estabelecer identidades (individuais ou coletivas) positivas, de uma clara ligação ao espaço e de um orgulho; outros, por seu lado, constroem uma espécie de identidade negativa, em que são apenas o que os outros não são. A grande questão é até que ponto a reprodução e disseminação de uma identidade negativa, assente em ressentimento, poderá ser frutuosa no curto/médio prazo ou apenas servir para criar uma lógica de comunitarismo. Por outro lado, esta crítica social não é apenas direcionada para o Outro, mas também para dentro, para aqueles que vivem em bairros e que são passivos. O propósito é despertar a revolta daqueles que estão na mesma situação que eles (GUERRA, 2019). Por outro lado, não se pode analisar as preocupações com o direito à cidade do rap escamoteando a questão da etnicidade (SIMÕES, 2017). Barbio (2011) considera inclusivamente que a etnicidade se encontra no código género do rap. Não só pela elevada percentagem de músicos oriundos das antigas colónias africanas, mas também pelo facto de muitas das canções terem claras influências africanas, de sons africanos e de letras cantadas em crioulo.

Estas estratégias de contestação existem em muito devido à particularidade da sociedade portuguesa no período pós-colonial. Fradique (2003), a respeito, afirma que a sociedade portuguesa é marcada não só por um recalcamento da história colonial recente, como também 
pelo silenciamento das vozes que viveram essa história colonial. Esse silenciamento deu origem à necessidade de se tornar visíveis. E como aconteceu em outros países com passado colonial, verificou-se que as segundas e terceiras gerações recusam o enquadramento que os seus progenitores tinham e desejam para eles uma posição de maior visibilidade. E que melhor maneira de alcançar essa visibilidade de que através da música?

E mais do que isso. Por vezes fala-se sobre a despolitização das populações e talvez o problema seja o enfoque de análise. Ainda existe uma sobre-análise relativa à participação política em partidos ou movimentos sociais de causas, que, como sabemos, são geralmente compostos por agentes com elevados capitais culturais e académicos. Bayat (2013) fala, por outro lado, social non-movements, quando a mobilização, resistência e discursos políticos surgem em contextos aparentemente não políticos. Se não mudarmos o enfoque teórico para estes grupos de jovens, ou se continuarmos a aplicar os mesmos padrões de análise que acionamos para um partido político, não conseguiremos apreender como os jovens de classes baixas, deserdados nas cidades da marginalidade avançada, têm o potenciar para se tornarem atores políticos. É, assim, necessária uma análise fina em atividades que podem não parecer políticas, mas que aquando estudadas nos permitem vislumbrar as suas dinâmicas políticas, especialmente relacionadas com o espaço urbano, racismo ou falta de oportunidades.

Existe, acima de tudo, uma culturalização do político. Os jovens utilizam o rap para estabelecerem os seus discursos (politizados) sobre a realidade. O rap serve para que eles se posicionem politicamente. Politizar-se é tornar-se visível. Willis (1990) constata que as produções culturais juvenis, como músicas, servem para que as suas ações sejam reconhecidas como práticas materiais e simbólicas significantes e significativas. Para García e Feixa Pàmpols (2020), são importantes estratégias de desmarginalização, especialmente relativamente à marginalização política. Resumindo, trata-se de estratégias de politização com significados locais, o que não impede que estes sejam contraditórios e até opostos.

Assim, um género como o rap é utilizado para demonstrar a situação estigmatizadora em que vivem. Aqui o rap implica um eixo estruturante e estruturador das identidades coletivas destes jovens; em seguida, corporiza uma oposição à sociedade em geral, e em particular algumas instituições, como o Estado ou as forças policiais; por fỉm, existe a preocupação com a visibilidade. Uma das principais lutas passa por uma visibilidade na cidade, onde estão todas as 
oportunidades. Recusam a (in)visibilidade a que foram votados, esquecidos na não-cidade (BARBIO, 2011).

\section{Subsídios para uma pedagogia rap}

Através do rap é possível constatarmos que um novo mundo está a ser criado. Trata-se de uma crise desumanizada que desemboca numa sociedade individualista e egoísta. Uma sociedade em que os piores instintos surgem: o medo e ódio face ao outro, o fechamento segundo linhas étnicas, o anti-intelectualismo e subsequente crescimento do populismo e das fake news (SANTOS; GUERRA, 2017). É sabido que a educação é um meio de combater esta questão. Porém, como bem demonstraram os trabalhos de Bourdieu e Passeron (1978), o sistema de ensino está na base dos mecanismos de reprodução social, operando para manter o status quo e as suas desigualdades. Uma abordagem complementar foi postulada por Freire (2005). Este filósofo critica o processo de depositar acriticamente o conhecimento do professor para o aluno através de uma relação não-comunicativa. Tal seria o oposto da verdadeira educação e apenas torna os alunos meros depósitos de informação destituídos de humanidade. A humanidade apenas surge através da invenção, da crítica impaciente, da criatividade de pensar novas formas de mudar o mundo e as relações entre as pessoas.

Freire (2005) propõe uma educação que nunca cessa de colocar questões, no sentido de uma futuridade revolucionária. Uma educação que ajude os indivíduos a se transcenderem a si mesmos através do conhecimento e da consciência do mundo à sua volta. Uma educação assente numa praxis humanista e libertadora, essencial para a emancipação e rutura do sentimento de crise identitária sentida, precisamente mais do que nunca, um pouco por todo o mundo. Trata-se, e perante os desafios e riscos que perpassam a atualidade, de reconhecermos como necessário avançar com propostas para uma pedagogia crítica e antissistema (SANTOS; GUERRA, 2017), assente em políticas e práticas educacionais que tenham em conta - no sentido da desconstrução - as relações de dominação e exploração na sociedade. Apesar de estarmos conscientes de que a ideia de uma pedagogia crítica ou antissistema possa provocar surpresas e até incompreensão, consideramos que a mesma envolve a potencialidade de ser inspirada pela perspetiva de um ethos do-it-yourself e de uma atitude confrontativa e de, por seu turno, provocar a emergência de estas 
preocupações no currículo escolar. De qualquer modo, o nosso propósito é recorrer ao universo dos possíveis que a música oferece como ideologia de oposição e consequente possibilidade de liberação dos constrangimentos do sistema educacional. Acima de tudo, tornar a escola num espaço de liberdade, ou seja, numa heterotopia simbólica.

Determinados géneros musicais, como o rap ou o punk rock, fornecem um contexto educativo e pedagógico alternativo em que as alunas e os alunos aprendem e produzem conhecimento relevantes para os seus contextos e experiências socio-históricos de atores marginalizados (SMITH; DINES; PARKINSON, 2017). Isto demonstra que existe uma potencialidade para que o processo educativo alternativo venha a romper com os discursos discriminatórios hegemónicos. Por tal, cremos que uma pedagogia rap passe por uma expressão de poder que rompa com as estruturas interligadas que sustentam o racismo, sexismo, neocolonialismo.

O rap, desde o seu surgimento nos Estados-Unidos, foi entendido como um veículo a adotar quer por educadores quer por assistentes sociais. Uma forma de alcançarem os jovens marginalizados e permitir que estes, através de discursos políticos plasmados nas letras rap, abordassem os problemas que afetavam as suas comunidades. Independentemente do nome que lhe quisermos dar, consideramos que o rap é um elemento-chave para renovar as práticas educativas e pedagógicas na atualidade. Especialmente quando comparamos esta pedagogia alternativa àquelas que têm feito caminho nas escolas: modelos universalizantes e dissociados do contexto socio-histórico dos jovens, incapazes de se abrir às culturas juvenis e aos seus saberes. Tudo isto se agrava quando entram em cena grupos sociais desfavorecidos, constatando-se que, em muitos casos, as medidas pedagógicas reforçam o problema, já que os caracterizam como problemas sociais que necessitam de integração (NONATO et al, 2016). Claro que isto não deixa de provocar reações. Existem alguns autores que referem certos estratos do rap, como o gangsta rap ou o grime, entendidos como disseminando niilismo e validação do crime e desvio (DICKENS; LONIE, 2013).

Apesar destas inquietações, na nossa perspetiva o rap tem pedagogicamente a capacidade de envolver a participação das e dos jovens através de uma agência musical. A aplicação desta pedagogia, através por exemplo de workshops, tem a faculdade de celebrar uma competência musical que no contexto escolar não é reconhecida (BYRNE; O'CONNELL; O'SULLIVAN, 
2020). O’Neill (2016) chama a isto transformative music engagement, que além de realçar as capacidades transformadores e empoderadoras da música, serve para que os jovens, entendidos como sujeitos ativos e produtores de conhecimento, consigam refletir e compreender realidades que não lhe são próximas, como as envoltas em problemáticas como o racismo ou a habitação degradada. O rap, através das suas letras interventivas e mesmo cruas, é, pensamos, um elemento potenciador.

\section{Uma metodologia alcachofra}

Calvino (1996) comparou a sociedade a uma alcachofra, com múltiplas camadas de análise, em que em cada uma descobrem-se novas dimensões de análise. Esta visão é o nosso princípio heurístico. Para nós, a sociologia da criação artística exige uma renovação que incorpore todas as suas potencialidades. Deve encarar cada obra como uma singularidade: em primeiro lugar, um facto social e artístico deve valer por si; segundo, cada obra deve ser entendida como um sistema (aberto) de sentido(s), como se fosse um texto, construído por um autor, em relação com outros textos e disponível para diferentes leituras; terceiro, cada obra tem de ser contextualizada através de uma relação com o mundo social. Estes eixos permitem desfolhar fecundamente as criações artísticas. Se a obra é entendida como singularidade, devemos considerar e valorizar analiticamente essa singularidade enquanto feixe único de múltiplas determinações; se for analisada enquanto texto, então deve ser compreendida (por referência ao seu próprio universo de sentido), interpretada (por mediação entre universos de sentido) e explicada (a outrem; e por colocação em relação com outros factos sociais); por fim, se for entendida como relação com o mundo, então são inúmeros os modos como se pode relacionar com o mundo: como conhecimento, representação, interpretação, imaginação ou valoração social.

O posicionamento enunciado remete para uma abordagem metodológica que, por economia de espaço não podemos expor na sua totalidade (FEIXA; GUERRA, 2017). No propósito que aqui nos retém, este trabalho pauta-se por demonstrar de que forma as manifestações artísticas constituem matéria e objeto de intervenção social, demarcando um espaço próprio, definido e específico na denúncia e revelação de problemáticas sociais e na contestação, protesto e revolta perante a realidade social. Ainda, a nossa opção metodológica 
passa pela análise de conteúdo categorial, que se trata de uma técnica fundamental para obter informações e regularidades sobre as condições de produção ou receção dos meios que podemos analisar (GUERRA, 2020). Um dos maiores erros da sociologia da criação artística é o pressuposto da correspondência harmoniosa entre estruturas. Daí, a necessidade de, antes de mais, reter algumas achegas metodológicas para evitar potenciais falhas. Primeiro, é o nosso olhar analítico que define e delimita o corpus; segundo, os procedimentos de categorização sociológica integram a análise sociológica da categorização social - a qual, por sua vez, tem em conta a evolução sócio histórica da categorização social; terceiro, o texto sociologicamente relevante da obra artística constrói-se em vários planos; quarto, é necessário se relacionar as estruturas artísticas (das obras artísticas) não apenas com as estruturas sociais, mas também com as estruturas culturais.

Por conseguinte, no caso em apreço, procurou-se captar uma nova vertente da canção de protesto, mas nas suas modalidades contemporâneas, assentando o corpus de análise num conjunto de quatro canções rap portuguesas: Reghetização, de General D (1997); Nada a perder, de Valete (2002); Bairro Black, de Allen Halloween (GENERAL D; BUTS MC, 2015); e National Ghettographik, de Chullage (2004). A escolha destas bandas e/ou artistas e canções teve por base duas ordens de razão: a primeira tem a ver com a notoriedade das canções e dos intérpretes no cenário musical do rap português; a segunda razão assenta nas temáticas que lhes estão subjacentes: a luta pela cidade e o desejo de uma nova urbanidade. O rap, enquanto movimento urbano, dedica uma grande atenção à dinâmica urbana, nomeadamente a rejeição da não-cidade a que os protagonistas das narrativas estão votados (FRITH, 1996).

\section{Bairro Gueto: parece inventado mas isto acontece deste lado}

Comecemos pela música Reghetização, de General D. Na década de 1980, Portugal ingressara na Comunidade Económica Europeia (CEE). Essa época foi também a primeira vez que Portugal passou de um país de emigrantes para um de imigrantes, especialmente oriundos das antigas colónicas africanas. A cidade de Lisboa rapidamente se tornou uma cidade multicultural e um grande centro de música africana. Em pouco tempo, o rap foi apropriado por certas elites, políticas e culturais, como bandeira de um novo Portugal multicultural e cosmopolita (FRADIQUE, 2003). Em 1997, altura em que esta música foi editada, torna-se óbvio o falhanço 
das políticas habitacionais e sociais para receber os imigrantes. Além de uma profusão de barracas ilegais nas periferias de Lisboa, assistiu-se à construção de bairros sociais com poucas condições de habitabilidade, poucas infraestruturas e acima de tudo gizados numa lógica de segregação, de afastamento destas populações do centro.

General D chama-lhe reghetização. O prefixo é relevante nesta análise. Na primeira fase da chegada destas populações imigrantes, estas foram-se estabelecendo aos poucos em diferentes localizações (MALHEIROS et al., 2007). A que se seguiu uma política urbana de concentração destes diversos núcleos populacionais em bairros sociais de grandes dimensões. Isto teve dois objetivos. Primeiro, concentrar as populações imigrantes num só local, com claros propósitos de uma maior facilidade de controlo securitário e segundo, acima de tudo:

Ghettos, bairros degradados, desmoronados transportados para outros lados/

$\mathrm{O}$ que eu quero dizer é que não adianta esconder gente em blocos de cimentos para inglês não ver a pobreza que vai no país/

Não dá para ignorar, isto é um problema de raiz (GENERAL D, 1997).

O Portugal recém-entrado na CEE, multicultural e moderno, não podia aceitar o pulular de pequenos bairros degradados pela capital. Tal explica, em parte, o afastamento, e consequente invisibilidade, a que foram votadas estas populações para as periferias de Lisboa. Esta mobilização das populações - "transporte" ("Ghettos, bairros degradados, desmoronados transportados para outros lados”) - merece outra consideração. Primeiro, a situação atual cantada por General D é tão má, que a anterior, também negativa, é olhada com saudosismo.

Já não tenho mais bairro, a minha casa está no chão direito

Foi aqui que nasci, vivi, desenvolvi o meu jeito, jeito de ser e de aparecer, de escrever Ao menos aqui éramos bem tratados, não havia brancos, pretos ou mulatos nem desgraçados.

Éramos pobres, mas não coitados (GENERAL D, 1997).

Dantes a vida podia ser pérfida, mas pelo menos existia num contexto de fortes sociabilidades. Essa constatação do músico remete para o facto de a concentração espacial das e dos imigrantes limitar os seus universos de possíveis (WACQUANT, 2009). Reduzindo o contacto com a população autóctone, isto acaba por limitar a participação na sociedade. Sendo, como referido por Malheiros et al. (2007) o grande problema de tudo isto o facto de a segregação étnica estar associada à segregação social. Cria-se uma homogeneidade nivelada por baixo, que estreita não só o contacto com indivíduos dotados de capitais sociais e relacionais. Tudo isto 
desemboca em guetos de exclusão que reproduzem fenómenos de exclusão, desemprego, insucesso escolar, entre outros. E vivencia-se, como canta General D:

Agora andamos escondidos, metidos em pisos sem janelas

Não dão para espreitadelas, mal dão para respiradelas (GENERAL D, 1997).

De referir que esta composição surge na primeira fase de habitação nesses bairros. $O$ facto de serem ainda edificações muito recentes não permitia laços de sociabilidade muito fortes entre os habitantes, daí também a desolação que perpassa as letras de General D. A decisão urbanística em questão evidencia o objetivo político já assinalado e, concomitante, uma dimensão racial:

Yo, yo, em pouco tempo os blocos serão esqueletos de casas, zaragatas, de gente assanhadas porque não há pão

E quando não há pão, há confusão e bandalhão de polícias esperarão altura para pôr na prisão ou então espancarão aqueles que digam "não"

Que falem alto, reclamem direitos de cidadão (GENERAL D, 1997).

Esta dimensão política resulta e traduz-se no afastamento urbano para longe do centro tem um resultado primordial: o silenciamento. O não-centro é o lugar do não-acontecimento. Se todas as infraestruturas estão no centro, tudo o que acontecer fora daí é um não-acontecimento. Direitos, manifestações surgem como ecos que não chegarão a grande parte da população. Por seu turno, a problemática do racismo surge como inerente. Daí o questionamento do General D: Para quê oferecer casas se são incapazes de encontrar um emprego? Para quê medidas paliativas se o racismo ainda é prevalecente, plasmado no insulto "preto"?

Não quero um bloco de cimento nem sequer um monumento, dá-me só um lar para construir o meu assento

Para quê nova casa se não me dão emprego

Para quê novo bairro se ainda me chamam de preto (GENERAL D, 1997).

A música Bairro Black, de Allen Halloween (feat General D e Buts Mc) segue o mesmo tom da anterior, mas com uma diferença significativa: a ênfase na violência policial. O problema começa quando estes espaços deixam de ser espaços de não-acontecimentos para se tornarem espaços de acontecimentos sensacionalistas e securitários (COHEN, 1972). Quem analisa estes espaços rapidamente se apercebe que as notícias que surgem sobre estes locais são sempre negativas: rusgas políticas, tráfico de droga, carros incendiados, etc. Entra-se num círculo vicioso de notícia sensacionalista, forte presença securitária, mais notícias sensacionalistas e assim sucessivamente (GUERRA, 2003). 
Isto tem de ser enquadrado numa lógica de criminalização da pobreza e do fenómeno da marginalidade avançada, como postulado por Wacquant (2009). Esta nova marginalidade concentra-se em territórios específicos e isolados do resto da cidade, vistos por quem é de fora, e mesmo por quem lá habita, como locais a evitar, onde reina a violência, pobreza e degradação. Isto pode ser em parte explicado por dois fatores: primeiro porque a pobreza e desigualdade estão normalmente associados a uma imobilidade física, os indivíduos afetados estão fixados aos seus contextos de vivência próxima; o segundo fator, e de extrema importância, é que estes bairros de relegação são produtos da estratificação levada a cabo pelo Estado. Wacquant (2014) considera mesmo que na marginalidade avançada é impossível de destrinçar a penalização da pobreza da etnicização. Tratam-se de duas formas de desvalorização e de desonra. As consequências são as atividades extralegais estatais nesses bairros. Continuando com Wacquant (2009), o que acontece é que o Estado institui a estas categorias sociais uma ordem de desvalorização social, o que possibilita (e justifica) os cortes nas suas oportunidades de vida, seja no emprego, na habitação, na progressão social, etc.

Quando a única instituição estatal entra é a polícia, o resultado são as eufemisticamente apelidadas ações musculadas. Estas medidas contribuem a médio prazo para agravar os sentimentos de revolta e de violência. É contra isto que os cantores se insurgem. $\mathrm{O}$ que os cantores fazem é inverter a lógica simbólica. Primeiro fazem um relato da situação:

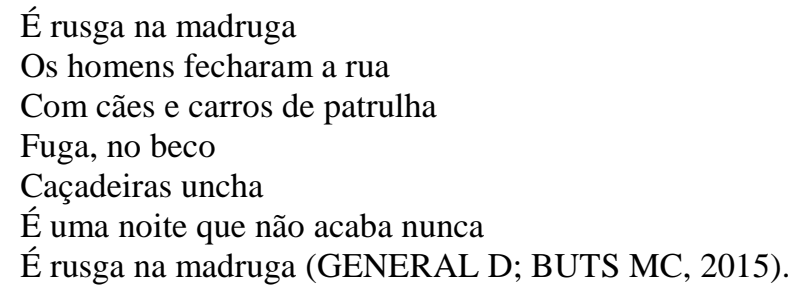

Depois, sim, temos a inversão da lógica simbólica. A ação não é enquadrada numa lógica securitária e legal e é apelidada como “abuso". Em seguida, a morte que resultou desta ação não é analisada como uma solução limite em que o polícia teve de se defender. É descrita como:

Eliminado por um agente do Estado

Era bandido, era mitra, era nigga

Tinha problemas com a justiça (GENERAL D; BUTS MC, 2015). 
Depois existe a cobertura jornalística. O jornalista não se desloca ao bairro, mas a história é lhe "encomendada". E o enquadramento que este dá à notícia segue as linhas sensacionalistas de um pânico moral: o indivíduo baleado não foi morto, mas sim "eliminado", não por um "polícia", mas por um "agente do Estado". Mas, acima de tudo, a causa desta sorte encontra-se nas características da vítima: bandido, "mitra", negro e com "problemas com a justiça". Enfim, a morte justifica-se. Os cantores não partilham essa opinião e declaram que se tratou pura e simplesmente "Mais um puto d'um bairro degradado assassinado".

Como já dissemos, um efeito desta estigmatização é a justificação de medidas especiais e extralegais. Os rappers narram o mesmo. De igual modo, como Wacquant (2014) constata, a violência extralegal que a polícia aciona, e narrada na canção, apenas pode ser compreendida se existir uma cobertura para estas práticas, o que novamente nos leva para as narrativas que se gizam em torno destes bairros. Numa lógica bélica, estes jovens passam a estar estigmatizados, alvos de uma generalização criminal, que os torna a todos potenciais "bandido, mitra e nigga".

Guerra (2003) afirma que quando se analisa a cobertura mediática, se constata que os jovens são destituídos de densidade individual e são apenas analisados enquanto categoria social (estigmatizada). Os jovens estigmatizados, para contrariar estas posições, tendem a se defenderem de um exterior entendido como inimigo (média, polícias, sociedade no geral). Como Goffman (1990) nos relata, este comportamento é expectável, pois os estigmatizados, face à hostilidade do mundo exterior, procuram o contacto de outros estigmatizados, criando, desta forma, mundos alternativos.

Ao contrário da canção anterior, esta tem um teor mais agressivo, mas que não deixa de estabelecer um diálogo interna e externamente. Logo no começo da canção o narrador não deixa de desabafar: "Parece inventado, mas isto acontece deste lado", não deixando de estabelecer o contraste entre o Nós/Eles, sendo o "eles" o espaço em que não é usual rusgas policiais de madrugada e onde jovens não são regularmente mortos pela polícia. Contudo, acima de tudo é uma mensagem para o interior, para os seus pares. Um apelo à revolta. Em dois momentos diferentes. Primeiro, quando se questiona:

E vai matar até quando?

Até o circo pegar fogo, mano

Porque o juiz é um palhaço (GENERAL D; BUTS MC, 2015). 
Acima de tudo, e atentando nas palavras de General D, que descreve memórias pessoais de algumas rusgas e dos efeitos que tiveram, relatando as "balas perdidas", a violência contra a família e a vizinha, etc., evidencia-se uma vivência pessoal inequívoca. Trata-se de uma forma de personalizar a narrativa, em que se partilha dados biográficos, aos quais - supõe-se - os ouvintes se consigam relacionar. Isto porque a música é talvez o meio significativamente eficiente e profícuo para exprimir frustração e divulgar essa mesma frustração a inúmeras pessoas. Neste caso, a expressão articula claramente um sentimento de pertença ligado à desvalorização étnica e social e novas alternativas que refutam a narrativa dominante que os estigmatiza (GOFFMAN, 1990). A música termina, porém, com uma atitude de desafio que é a resposta à violência policial: "Eu nunca fujo".

\author{
Abuso sujo, é o cheiro do cartuxo \\ Uma noite muito longa no bairro onde me refúgio \\ Eu nunca fujo (GENERAL D; BUTS MC, 2015).
}

\title{
6 O crioulo é a minha pátria: capital (sub)cultural racializado
}

Said (2003), na década de 1970, falou do orientalismo. Isto é, do exotismo existente na visão ocidental sobre determinados povos. Essa perspetiva ainda existe em muitas reportagens jornalísticas, como aquelas que relatam a miséria e fome, nomeadamente, em países africanos. Ora, com as migrações para os países ocidentais, em muitos casos esse exotismo voltou-se para dentro. As mesmas representações foram aplicadas agora a grupos minoritários. É sobre isso que fala a música National Ghettographik, do rapper Chullage. Jogando com as palavras National Geographic e ghetto, o músico demonstra a visão de uma parte da população portuguesa, e de vários média, sobre os bairros estigmatizados.

\footnotetext{
De perto ou de longe, qualquer ângulo, qualquer plano eu faço o zoom

É a realidade dos guettos que aqui se resume

Na escola não se lê

Não mostra na TV

Mas só quem não quer é quem não vê

National ghettographik, lisa, Margem Sul e r.e.g (CHULLAGE, 2004).
}

Trata-se de um problema inerente à construção de pânicos morais. Por um lado, oculta-se a realidade; por outro, exagera-se a construção de categorias sociais de interpretação que 
promovam as famosas cruzadas morais (e securitárias) nestes bairros. Como Becker (2018) refere, os média são essenciais para o sucesso de uma cruzada moral, quer por acionarem um processo de sensibilização quer pela amplificação face ao desvio. É deles o papel de agentes de indignação moral, divulgando notícias que geram preocupação e ansiedade na população e, por conseguinte, criam os problemas sociais (COHEN, 1972). Se a isto juntarmos a preocupação com as audiências, compreendemos a aposta no sensacionalismo que quase sempre acompanha as reportagens sobre os bairros sociais: sempre repletas de moralismo e psicologismo (GUERRA, 2003). Chullage, apropriando-se dessa lógica, subverte-a. Realiza na música uma reportagem à la National Geographic. Não sobre animais na savana, mas sobre os jovens nos bairros degradados. A meio da canção, contudo, não deixa de fazer um reality check para constatar "Não há ficção, não há efeitos especiais, rap é o soundtrack registo criminal é o cartaz”. Apontando a lente para os guetos, o que se vê? Uma população jovem sem oportunidades. Jovens que apenas conseguem trabalhar na construção civil, com contratos precários, e em muitos casos nem pagos são:

\author{
Mais incertezas, mais agonia \\ Mais uma marmita \\ Rumo a uma obra onde o f.d.p é capaz de bazar no fim do mês com a guita \\ (CHULLAGE, 2004).
}

Por outro lado, em sintonia com as duas músicas anteriores, fala-se também da degradação urbana em que se vive, o que se reflete numa interiorização de um destino de etnoclasse (MALHEIRO et al., 2007). E arremessados para (n)estes bairros, afastados de tudo, todos caem aos pedaços:

\footnotetext{
A verdadeira dimensão só quem a vive mede-a No meio de barracas e prédios sem portas nem elevadores Com tags pelas escadas e corredores onde ratos e outros parasitas coabitam com o resto dos moradores. Roupas rasgadas penduradas nas janelas (CHULLAGE, 2004).
}

Pela primeira vez nas canções que analisamos existe uma referência à geração paterna. Até então apenas ouvimos falar sobre os jovens e as suas necessidades. Agora entram em cena as mães e os pais, especialmente a sua luta infrutífera para manter os filhos no "caminho certo". Longas horas de trabalho, prédios em altura que impedem uma relação mais próxima, tudo fatores que faz o "perigo" estar perto. E um pouco como nos programas da National Geographic, também aqui existe uma lei da selva, mas esta com o resultado já escrito de antemão: 
Crianças inocentes girando à volta de mães solteiras. Babillones

Em rondas rotineiras. Procuram a razão p'ra sairem de caçadeiras na mão

Cotas que voltam depois de mais um dia de luta pelo pão, sem saber o paradeiro dos

familiares. Sem saber a razão dos insucessos escolares

De filhos que eles tanto lutam p'ra manter no caminho certo

Mas enquanto os pais estão longe, o perigo está perto (CHULLAGE, 2004).

Acima falamos da divisão entre identidades positivas ou negativas cantadas pelo rap. Apesar de ser fácil ver aqui o desenvolvimento de um etno-grupo ou etno-classe, um conceito que geralmente se encontra associado a receios de criação de sociedades paralelas e culturas antagonistas. Porém, não nos podemos ficar por aí. Um etno-grupo é também uma comunidade como qualquer outra: possuem práticas, relações e valores que se cristalizaram devido ao cruzamento das vidas individuais e coletivas dos seus membros. Baseiam-se na criação de laços de solidariedade, essenciais para a manutenção de qualquer identidade duradoura, mas acima de tudo quando estamos perante uma comunidade em luta contra processos de exclusão e marginalização. Um dos exercícios gizados para esta luta passa pela manutenção da identidades étnica, e com tudo o que esta comporta. Como sabemos, a língua é uma questão essencial para a manutenção identitária. Daí a opção consciente pelo crioulo, que vamos analisar de forma detalhada.

Detenhamo-nos antes na expressão "Babillones", uma corruptela de "Babilónia". Na segunda música analisada, Bairro Black, também surge palavras em crioulo. Estamos na presença do que Halliday (1976) apelida de antilinguagem. O que quer dizer Babilónia? Primeiro de tudo, é um termo bíblico. O povo que durante o reinado de Nabucodonosor conquistou o reino de Israel, destruiu o templo e escravizou a sua população. A Babilónia, neste caso em concreto, é o Estado português. De igual modo, a utilização do crioulo como veículo de reforço identitário, já que apenas pode ser entendida por um reduzido número das pessoas que a escutam. $\mathrm{O}$ que também pode ser entendido como uma lógica de luta contra a Babilónia. O rap, como vemos, segue à letra este preceito e através do crioulo cria um espaço de resistência que a Babilónia pura e simplesmente não consegue entender. Souza (2016) considera-o um exemplo de um Pretugal, musica de CHULLAGE (2004), em que a população negra não só exige voz, como exige falar na voz que quiser.

A questão do crioulo tem outras particularidades. Na nossa opinião é uma forma qualitativamente diferente do capital subcultural (THORNTON, 1996). Concerne a um capital 
subcultural racializado e excludente. Enquanto o capital subcultural é apreensível por todas as pessoas com interesse (e tempo livre) para incorporar o saber-fazer característica de cada cena musical, esta forma de capital é excludente e dirigido apenas para uma reduzida franja da cena rap portuguesa. É a própria afirmação da personalidade racializada, da negritude, que, por seu turno, não deixa de criar desequilíbrios e paradoxos na cena rap nacional, esta, atualmente, bem mais ampla do que a associada às realidades que temos vindo a salientar e a compreender neste texto. Estamos, portanto, perante uma cena musical em que uma parte dos seus membros, alguns dos quais com posições centrais e com elevados capitais subculturais, pura e simplesmente não consegue entender a mensagem que outros pretendem passar.

A linguagem é dos fenómenos mais excludentes. Daí que optar por colocar a música, ou partes dela, em crioulo, é uma opção consciente por parte dos intervenientes: a exclusão que provoca é procurada. É uma forma de inverter a lógica geral de exclusão que sentem por parte da sociedade. Todavia, é crucial nos questionarmos se não será isto um fim em si mesmo, uma vez que o capital subcultural clássico, como as restantes formas de capital, pode ser convertido noutros campos sociais. Nesta linha, Guerra (2018) analisa como os capitais subculturais apreendidos na cena do-it-yourself portuguesa são reconvertidos em trajetórias profissionais, comprovando a reconversão de um campo para o outro. Por outro lado, o capital subcultural racializado não permite uma conversão para outros campos. O que nos conduz a questionar até que ponto esta opção não denota um fechamento social de um grupo social por si já estigmatizado. Por outro lado, também não deixa de implicar, como acima falámos, da necessidade de acionar um aglutinador identitário e uma expressão de alteridade. Um direito à diferença, que serve para dar mais visibilidade à sua existência.

Valete (2002), por outro lado, na sua canção Nada a perder, relata a ocupação urbana levada a cabo pelos jovens oriundos dos bairros sociais e que tanto temor provoca no resto da sociedade. Mas, apesar de não podermos escamotear a relação com os pânicos morais, pensamos que a análise se torna mais fina se analisarmos através de uma perspetiva baseada na preponderância dada por estes jovens ao capital de virilidade.

Ontem pequenos rebentos, hoje corações sangrentos

putos sub-16, as ruas são os seus apartamentos

vêm daqueles bairros de má-fama, bairros problema

onde repórteres do drama, não conseguem desligar a câmara

$[\ldots]$ 
mas eles sabem que respeito nas ruas não é só para quem tem testículos também é necessário, aparecer na esquadra para encher currículo isto é a legislação das ruas e fraquejar é sacrilégio (VALETE, 2002).

Estas estratégias de enfrentamento e de ocupação do espaço urbano têm de ser relacionadas com a valorização de um capital de virilidade por parte dos jovens nestes bairros. Como já foi analisado para outras realidades, como o no caso do punk (FEIXA; GUERRA, 2017), quando se processam fenómenos de desvalorização social, com percursos marcados por trajetórias sociais descendentes ou exclusão social, em muitos casos tudo o que resta é a força física. O que se torna um capital em si e altamente valorizado. Por outro lado, a virilidade por si só nada vale, é necessário que seja certificada por outros homens, através, nomeadamente, de vários rituais de instituição. É nestes rituais que os indivíduos são postos à prova e demonstrem a sua virilidade, a sua coragem, para desta forma passarem a fazer parte do grupo dos verdadeiros homens (BOURDIEU, 2013).

Mais relevante é como a letra termina: "eles sabem que não têm futuro, mas eles têm o presente". Praticamente resume tudo o que dissemos até ao momento. Quando se vive numa situação limite, não apenas momentânea, mas estrutural - em que as possibilidades de progressão social são nulas, em que as possibilidades de emprego estáveis são escassas; numa sociedade em que olha para eles como um grupo social homogéneo sempre pronto a cometer crimes e delinquência -, não vale a pena olhar o passado, uma vez que justifica o presente periclitante. E quando não se consegue obter um emprego estável e bem remunerado, quando a precariedade e desemprego impedem que se façam planos, como olhar para o futuro? O presente pode ser mau, mas é o que resta a estes jovens.

\section{Eu nunca fujo: pistas conclusivas}

Esta análise é possível porque previamente se optou por imaginar uma solução para os problemas analisados. Isto é, tal como a pedagogia antissistema, pretendeu-se resolver um problema. No fundo, imaginar novas possibilidades. Calvino é um autor com uma profunda vertente pedagógica (e sociológica). Em As Cidades Invisíveis ele narra a chegada a uma cidade: Fedora. Uma cidade sombria, cinzenta, mas com um palácio que possui uma secção com múltiplas esferas em vidro, nas quais se encontra - em cada uma-uma diferente Fedora. Em 
todas as épocas, habitantes dessa cidade imaginaram uma Fedora ideal: uma Fedora mais igualitária, uma Fedora sem violência ou uma Fedora com um aquário de medusas. Isto faz com que o narrador diga a Kublai Khan, a quem se dirige, que no seu império deveriam constar todas as putativas Fedoras, não por serem verdadeiras, mas sim por serem o que num dado momento as pessoas acharam necessário e imprescindível.

Em nosso entender, tal como acontece em Fedora - onde se abre possibilidades e ensejos - o objeto da pedagogia rap assenta em novas possibilidades para a sociedade. O que implica, antes de tudo, conhecer a nossa realidade, conhecer as suas desigualdades, e depois avançar para a sua resolução. O rap, precisamente, tem essa potencialidade: ao constituir-se num amalgamar de múltiplas realidades e abrir inúmeros níveis de interpretação. Mas acima de tudo, o propósito deste género de pedagogia é não acabar como a cidade de Fedora, que não conseguiu ir para além das possibilidades, acabando cinzenta e com os seus habitantes a visitar o palácio e a observar tristemente como a sua cidade poderia ser. O propósito inerente à proposta pedagógica que discutimos e propomos é, primordialmente, incutir um espírito crítico e transformador, e que os jovens têm opiniões, não são um massa desmobilizada politicamente - tudo o que precisam é de quem os ouça e lhes dê instrumentos criativos e originais para expressarem as suas posições (BYRNE; O’CONNELL; O’SULLIVAN, 2020). O rap surge, então, como um fortíssimo instrumento pedagógico a introduzir nos sistemas de educação de formal, como a escola.

$\mathrm{Na}$ verdade, defendemos a utilização das culturas juvenis como uma profícua estratégia pedagógica. É necessário compreender as culturas juvenis e a realidade dos jovens e envolver essas histórias/perspetivas nos currículos, uma vez que já não os parece ser mais possível e exequível separar a vida extraescolar da vida escolar. Não é possível esperar que os jovens deixem a sua cultura e experiência de vida às portas da escola. Byrne, O'Connell e O'Sullivan (2020) falam da possibilidade de aplicar o rap a praticamente todas as áreas de educação. Veja-se o exemplo das Science Genius Battles, um programa educativo focalizado em demonstrar como pode o rap influenciar os jovens para a ciência. É apenas um exemplo, mas que serve para demonstrar como se pode utilizar o ritmo do rap como instrumento pedagógico em contraste com o paradigma tradicional de aula expositiva. Ou os workshops de rap que servem para jovens desfavorecidos expressarem as suas opiniões sobre o espaço urbano. E de uma forma que dá espaço ao jovem, já que o rap permite que os jovens se expressem num contexto em que se 
sentem confortáveis, geralmente com o seu grupo de pares, e assim expressando opiniões que de outro modo não o fariam (BRAGG, 2007).

Já o afirmámos e agora reiteramos: Calvino é um escritor com um pendor sociológico. Especialmente se nos focarmos nos seus textos sobre as cidades. Uma das citações mais conhecidas de Calvino remete para a necessidade de não deixarmos mumificar os problemas. Os problemas, seja da cidade ou da necessidade de um novo paradigma pedagógico, parecem tão inultrapassáveis que em muitos casos surgem como para além das nossas forças. Combater este sentimento é uma opção dolorosa, que necessita de uma constante atenção e trabalho. Numa situação como essa, para Calvino existem dois modos de atuação:

O primeiro torna-se fácil para muita gente: aceitar o inferno e fazer parte dele a ponto de já não o vermos. O segundo é arriscado e exige uma atenção e uma aprendizagem contínuas: tentar e saber reconhecer, no meio do inferno, quem e o que não é inferno, e fazê-lo viver, e dar-lhe lugar (CALVINO, 2009, p. 177-178).

A nossa opção é simples: criar opções pedagógicas, como acima referido, capazes de criar espaços para reconhecer o que não é inferno e fazê-lo viver. Tal apenas é possível através de um processo constante de inclusão das vozes das e dos jovens a partir de estratégias em que possam ativar a sua agência de uma forma confortável que lhes permita refletir e questionar as suas experiências quotidianas e identidade.

\section{Bibliografia}

AUGÉ, Marc. Não-Lugares. Lisboa: Letra Livre, 2012.

BARBIO, Leda. Jovens (sub)urbanos: o impacto do hip hop na produção de identidades sociais. Forum Sociológico, Lisboa, n. 21, p. 75-83, 2011.

BAYAT, Asef. Life as politics. Stanford: Stanford University Press, 2013.

BECKER, Howard S. Outsiders. Nova Iorque: Simon \& Schuster, 2018.

BOURDIEU, Pierre. A dominação masculina. Lisboa: Relógio D’Água, 2013.

BOURDIEU, Pierre; PASSERON, Jean-Claude A reprodução. Lisboa: Veja, 1978.

BRAGG, Sara. Consulting young people: a review of the literature. London: Arts Council England, 2007.

BYRNE, Lorcan; O’CONNELL, Cathal; O’SULLIVAN, Siobhan. Rap and political participation: using rap as a creative method in research with children and young people. YOUNG, Helsinki, Preprints:

Artigo publicado pela primeira vez online: 1 ago. 2019. Edição publicada: v. 28, n. 1, p. 50-68, fev. 2020. Disponível em: https://journals.sagepub.com/doi/10.1177/1103308819856755. Acesso em: 4 out. 2019. 
CALVINO, Italo. As cidades invisíveis. Sintra: Impala, 2009.

CALVINO, Italo. Seis propostas para o próximo milénio. Lisboa: Teorema, 1996.

CHULLAGE. National Ghettographik. In: RAPENSAR. Lisboa: Lisafonia, 2004. CD Álbum

CHULLAGE. Portugal. In: RAPENSAR. Lisboa: Lisafonia, 2004. CD Álbum

COHEN, Stanley. Folk devils and moral panics. London: MacGibbon and Kee, 1972.

DICKENS, Luke; LONIE, Douglas. Rap, rhythm and recognition: Lyrical practices and the politics of voice on a community music project for young people experiencing challenging circumstances. Emotion, Space and Society, New York, v. 9, p. 59-71, 2013.

FEIXA, Carles; GUERRA, Paula. Unidos por el mismo sueño en una canción: on music, gangs and bands. Portuguese Journal of Social Sciences, Lisboa, v. 16, n. 3, p. 305-322, 2017.

FRADIQUE, Teresa. Fixar o movimento. Lisboa: Dom Quixote, 2003.

FREIRE, Paulo. The pedagogy of the oppressed. Londres/Nova Iorque: Continuum, 2005.

FRITH, Simon. Performing rights. Oxford: Oxford University Press, 1996.

GENERAL D; BUTS MC. (feat). Allen Halloween - Bairro Black. In: HÍBRIDO. Lisboa: Sohiphop, 2015. CD Álbum

GENERAL D. Reghetização. In: PORTUKKKAL é um erro. Lisboa: Valentim de Carvalho, 1997. 1 CD.

GOFFMAN, Erving. Stigma. Londres: Penguin, 1990.

GUERRA, Paula. A cidade na encruzilhada do urbano: elementos para uma abordagem de um objecto complexo. Sociologia, Porto, v. 13, p. 69-119, 2003.

GUERRA, Paula. Raw Power: Punk, DIY and Underground Cultures as Spaces of Resistance in Contemporary Portugal. Cultural Sociology, London, v. 12, n. 2, p. 241-259, 2018.

GUERRA, Paula. 'The Song Is Still a 'Weapon': The Portuguese Identity in Times of Crises. YOUNG, Helsinki, Preprints: Artigo publicado pela primeira vez online: 9 maio 2019. Edição publicada: v. 28, n. 1, p. 14-31, fev. 2020. Disponível em: https://journals.sagepub.com/doi/10.1177/1103308819829603. Acesso em: 4 out. 2019.

GUERRA, Paula. Verdade e consequência no hip-hop português contemporâneo: o caso de Capicua. In: GUERRA, Paula; SITOE, Tirso. (orgs.). Reinventar o discurso e o palco. Porto: FLUP, 2019. p. 202219.

HALLIDAY, M. A. K. Anti-Languages. American anthropologist, Arlington, v. 78, n. 3, p. 570-584, 1976.

LEVIE, Mark. When art is the weapon: culture and resistance confronting violence in the post-uprisings Arab world. Religions, Suíça, v. 6, p. 1277-1313, 2015.

MALHEIROS, Jorge Macaísta et al. Espaços e expressões de conflito e tensão entre autóctones, minorias migrantes e não migrantes na área metropolitana de Lisboa. Lisboa: ACIME, 2007.

NONATO, Symaira Poliana et al. Por uma pedagogia das juventudes. In: DAYRELL, Juarez. (org.) Por uma pedagogia das juventudes. Belo Horizonte: Mazza, 2016. p. 249-304.

O'NEILL, Susan A. Youth empowerment and transformative music engagement. In: BENEDICT, Cathy; SCHMIDT, Patrick; SPRUCE, Gary; WOODFORD, Paul. (ed.) The child as musician: a handbook of musical development. New York: Oxford University Press, 2016. p. 606-625. 
SAID, Edward. Orientalism. Londres: Penguin Books, 2003.

SÁNCHEZ GARCÍA, José; FEIXA PÀMPOLS, Carles. My name and the name of all people who live in misery: rap in the wake of revolution in Tunisia and Egypt. YOUNG, Helsinki, Preprints: Artigo publicado pela primeira vez online: 30 out. 2019. Edição publicada: v. 28, n. 1, p. 85-100, fev. 2020. Disponível em: https://journals.sagepub.com/doi/abs/10.1177/1103308819868334. Acesso em: 4 out. 2019.

SANTOS, Tiago Teles; GUERRA, Paula. From punk ethics to the pedagogy of the bad kids: core values and social liberation. In: SMITH, Gareth Dylan; DINES, Michael; PARKINSON, Tom. (eds.). Punk Pedagogies, Londres, p. 210-224, 2017.

SIMÕES, Soraia. RAPublicar. A micro-história que fez história numa Lisboa adiada 1986-1996. Lisboa: Caleidoscópio, 2017.

SMITH, Gareth Dylan; DINES, Michael; PARKINSON, Tom. (eds.). Punk pedagogies. Londres: Routledge, 2017.

SOUZA, Angela Maria de. A caminhada é longa... e o chão tá liso: o movimento Hip Hop em Florianópolis e Lisboa. São Leopoldo: Trajetos Editorial, 2016.

THORNTON, Sarah. Club cultures. Middletown: Wesleyan University Press, 1996.

VALETE. Nada a perder. In: EDUCAÇÃO visual. Lisboa: Estúdios BigBit, 2002. CD Álbum

WACQUANT, Loïc. Deadly symbiosis. Cambridge: Polity Press, 2009.

WACQUANT, Loïc. Marginalidade, etnicidade e penalidade na cidade neoliberal: uma cartografia analítica. Tempo Social, São Paulo, v. 26, n. 2, p. 139-164, 2014.

WILLIS, Paul. Common cultures. Boulder: Westview Press, 1990. 